\title{
Correction to: Modified two-stage restorative proctocolectomy with ileal pouch-anal anastomosis for ulcerative colitis: a systematic review and meta-analysis of observational research
}

\author{
William Yu Luo $^{1} \mathbb{D} \cdot$ Siddharth Sing $^{2} \cdot$ Raphael Cuomo $^{3} \cdot$ Samuel Eisenstein $^{1}$ \\ Published online: 28 November 2020 \\ (C) Springer-Verlag GmbH Germany, part of Springer Nature 2020
}

Correction to: International Journal of Colorectal Disease (2020) 35:1817-1830 https://doi.org/10.1007/s00384-020-03696-7

The Family name of the first author in the reference no. 57 of the original version of this article was incorrectly spelled. The name should have been spelled as "Luo" instead of "Lou". The correct reference is as follows:

57. Luo WY, Holubar SD, Bordeianou L, Cosman B, Hyke R, Lee EC, Messaris E, Saraidaridis J, Scow JS, Shaffer VO, Smith R, Steinhagen RM, Vaida F, Eisenstein S, Ramamoorthy S, Hilbert N, Steinhagen R, Sylla P, Divino C, Miller R, Deutsch M, Scow J, Huggins P, Shogan B, Hyman N, Prachand V, Sullivan S, Hull T, Holubar S, Jia X, Anzlovar N, Bohne S, Lee E, Valerian B, Keenan M, Goyette A, Spain D, Hyke R, De Leon E, Saraidaridis J, Lewis WD, Golden T, Crawford L, Mutch M, Smith R, Hall B, Hirbe M, Batten J, Riccardi R,

The online version of the original article can be found at https://oi.org/ $10.1007 / \mathrm{s} 00384-020-03696-7$

Samuel Eisenstein

seisenstein@health.ucsd.edu

William Yu Luo

wyluo@health.ucsd.edu

Siddharth Singh

sis040@health.ucsd.edu

Raphael Cuomo

racuomo@ucsd.edu

1 Department of Surgery, Division of Colon and Rectal Surgery, University of California, San Diego School of Medicine, La Jolla, CA, USA

2 Department of Medicine, Division of Gastroenterology, University of California, San Diego School of Medicine, La Jolla, CA, USA

3 Department of Anesthesiology, University of California, San Diego School of Medicine, La Jolla, CA, USA
Bordeianou L, Kunitake H, Antonelli D, Swierzewski K, Devaney L, Messaris E, Whyte R, Ward M, Cotter MB, Shaffer V, Sharma J, Lewis J, Sitafalwalla S, Kapadia M, Kresowik T, Belding-SchmittM, Fichera A, Aguilar D, Mueller M (2020) Better characterization of operation for ulcerative colitis through the national surgical quality improvement program: A 2-year audit of NSQIP-IBD. Am J Surg. https://doi. org/10.1016/j.amjsurg.2020.05.035

The original article has been corrected.

Publisher's note Springer Nature remains neutral with regard to jurisdictional claims in published maps and institutional affiliations. 